\title{
Effects of Head Rotation and Head Tilt on Pharyngeal Pressure Events Using High Resolution Manometry
}

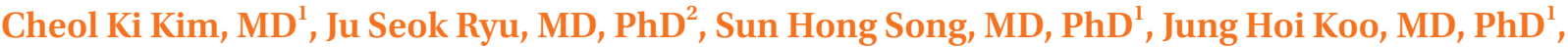 \\ Kyung Duck Lee, $\mathrm{MD}^{1}$, Hee Sun Park, $\mathrm{MD}^{1}$, Yoongul Oh, $\mathrm{MD}^{3}$, Kyunghoon Min, $\mathrm{MD}^{3}$
}

\begin{abstract}
${ }^{1}$ Department of Rehabilitation Medicine, Gangneung Asan Hospital, University of Ulsan College of Medicine, Gangneung;
${ }^{2}$ Department of Rehabilitation Medicine, Seoul National University Bundang Hospital, Seoul National University College of Medicine, Seongnam; ${ }^{3}$ Department of Rehabilitation Medicine, CHA Bundang Medical Center, CHA University, Seongnam, Korea
\end{abstract}

Objective To observe changes in pharyngeal pressure during the swallowing process according to postures in normal individuals using high-resolution manometry (HRM).

Methods Ten healthy volunteers drank $5 \mathrm{~mL}$ of water twice while sitting in a neutral posture. Thereafter, they drank the same amount of water twice in the head rotation and head tilting postures. The pressure and time during the deglutition process for each posture were measured with HRM. The data obtained for these two postures were compared with those obtained from the neutral posture.

Results The maximum pressure, area, rise time, and duration in velopharynx (VP) and tongue base (TB) were not affected by changes in posture. In comparison, the maximum pressure and the pre-upper esophageal sphincter (UES) maximum pressure of the lower pharynx in the counter-catheter head rotation posture were lower than those in the neutral posture. The lower pharynx pressure in the catheter head tilting posture was higher than that in the counter-catheter head tilting. The changes in the VP peak and epiglottis, VP and TB peaks, and the VP onset and post-UES time intervals were significant in head tilting and head rotation toward the catheter postures, as compared with neutral posture.

Conclusion The pharyngeal pressure and time parameter analysis using HRM determined the availability of head rotation as a compensatory technique for safe swallowing. Tilting the head smoothes the progress of food by increasing the pressure in the pharynx.

Keywords Upper esophageal sphincter, Manometry, Pressure, Deglutition disorders

Received July 30, 2014; Accepted October 23, 2014

Corresponding author: Ju Seok Ryu

Department of Rehabilitation Medicine, Seoul National University Bundang Hospital, Seoul National University College of Medicine, 82 Gumi-ro 173beon-gil, Bundang-gu, Seongnam 463-707, Korea

Tel: +82-31-787-7739, Fax: +82-31-787-4051, E-mail: jseok337@snu.ac.kr

(ㄷ) This is an open-access article distributed under the terms of the Creative Commons Attribution Non-Commercial License (http://creativecommons. org/licenses/by-nc/4.0) which permits unrestricted noncommercial use, distribution, and reproduction in any medium, provided the original work is properly cited.

Copyright $\odot 2015$ by Korean Academy of Rehabilitation Medicine

\section{INTRODUCTION}

Deglutition is a very complicated process controlled by the swallowing center in the medulla [1]. The deglutition process includes an oral phase, a pharyngeal phase, and an esophageal phase. Many problems in this process are found during the pharyngeal phase [1]. Many oropha- 
ryngeal and upper esophageal sphincter (UES) muscles are involved in the deglutition process. A neuromuscular disorder in the oropharyngeal area that controls these muscles, can cause a problem in the deglutition process [2].

In patients with oropharyngeal dysphagia, a videofluoroscopic swallowing study (VFSS) is useful for assessing structural or functional problems. The rapid sequence in the oropharyngeal swallowing process can be observed. In particular, the pharyngeal swallowing process is assessed to detect any pooling in the pyriform sinus or valleculae, and aspiration [2]. In addition to these functional assessments, pharyngeal pressure changes are assessed using manometry [3-5]. In the conventional manometric procedure, subjects experience discomfort due to the overly thick catheter, and the lack of sensors makes it difficult to observe the results for a specific area. The new high-resolution manometry (HRM) is useful for quantitative geometric analyses of accurate UES pressure change owing to the thin ( $4 \mathrm{~mm}$ diameter) catheter, 36 channels, and 12 sensors for each channel $[4,6]$.

Various compensation techniques, such as chin tuck, head rotation, head tilt, and the Mendelsohn technique, are used to treat dysphagia. These techniques decrease the risk of the aspiration and pharyngeal residual materials [7]. Rotating the head toward the affected side decreases, the anatomical space of the pyriform sinus, and food residue can be sent down the healthy side. Tilting the head towards the healthy side, a bolus can flow along the healthy side pharyngeal wall; these techniques can be applied for patients with unilateral pharynx or tongue weakness, such as in Wallenberg syndrome [8]. The two techniques can be applied depending on the patient's symptoms.

The mechanism of these techniques, which includes changing the patient's posture to aid the deglutition movements, is often assessed using the VFSS test [9]. Nevertheless, the VFSS is not enough to confirm changes in pharyngeal pressure and the effects of the pressure difference according to the posture. Manometry is used for pharyngeal pressure change after the head is rotated. As a result, the UES pressure decreases, which helps the bolus pass through the pharynx [6]. Rotating the head toward the affected side and tilting the head towards the sound side have been confirmed as useful in treating dysphagia, but few studies on UES pressure change have been re- ported thus far.

In this study, UES pressure changes according to compensation postures, such as head rotation and head tilt, compared with those at the neutral posture, were investigated using HRM. In addition, the pharyngeal pressure changes in the head tilt posture were compared with those in the head rotation posture.

\section{MATERIALS AND METHODS}

\section{Subjects}

Ten subjects participated in this study with the approval of the Institutional Review Board of the CHA Bundang Medical Center. All subjects were without swallowing, neurological, or gastrointestinal disorders. Participants were instructed not to eat for 4 hours and not to drink liquids for 2 hours before prior to testing to avoid any potential confounding effect of satiety. The average age of the 10 subjects was $29.2 \pm 7.2$ years old. Seven were male and 3 were female.

\section{Equipment}

The solid High-Resolution Impedance Manometry System (InSIGHT HRiM; Sandhill Scientific, Highlands Ranch, CO, USA) that can measure rapidly changing pressures along the entire length of the pharynx was used [10]. The manometric catheter uses 32 circumferential pressure sensors spaced $1 \mathrm{~cm}$ apart.

\section{Data collection}

Ten percent lidocaine spray was applied through the nasal passage. The manometric catheter was lubricated with $2 \%$ lidocaine jelly to ease passage of the catheter through the pharynx. Once the catheter was positioned within the pharynx, participants rested for 5-10 minutes to adjust to the catheter before they performed the experimental swallows.

In the neutral head position, the participants drank 5 $\mathrm{mL}$ of water unassisted 2 times.

\section{Data analysis}

Pressure and timing data were extracted using a BioVIEW Analysis software ver. 5.6.3.0 (Sandhill Scientific). The areas of interest were velopharynx (VP), tongue base (TB), lower pharynx (LP), and UES [11,12].

The VP, TB, and UES were defined manometrically 
as in McCulloch et al. [12]. The VP was defined as the area of the pressure changes associated with proximal swallowing immediately extending $2 \mathrm{~cm}$ beyond nasal continuous stationary area. The TB pressure was located anatomically at the same level as the epiglottis. The tilted epiglottis strikes the manometric catheter, thus tilting and epiglottis tilting results in changes $s$ in the peak pressure and area. Therefore, we measured the higher pressure peak at 1 level higher or lower than the epiglottis level, as the tongue base pressure. The LP peak was measured between the TB and the UES. This peak was shallow and peristaltic. The UES peak was broad, and located 1 channel below the LP peak. Therefore the LP peak represented the inferior pharyngeal constrictor and the UES peak represented the cricopharyngeus muscles (Fig. 1).

Mean and standard deviation values were recorded for maximum pressure, area, rise time and duration in the regions of the VP and TB. We measured maximal peak pressure in the region of the LP. In addition, we measured pre-swallow UES maximal pressure, post-swallow UES maximal pressure, minimal UES pressure, UES activity time (the interval between pre-swallow UES peak and post-swallow UES peak) and nadir UES duration in the region of UES. We also measured the time intervals between VP onset and epiglottis peak, VP onset and TB onset, VP peak and epiglottis peak, VP peak and TB peak, VP onset and pre-UES peak, and VP onset and post-UES peak. We calculated rate of pressure generation in $\mathrm{VP}, \mathrm{TB}$ (maximal peak amplitude / rise time) and pressure wave velocity (the distance from the VP pressure peak to the maximum post-swallow UES pressure peak / the time

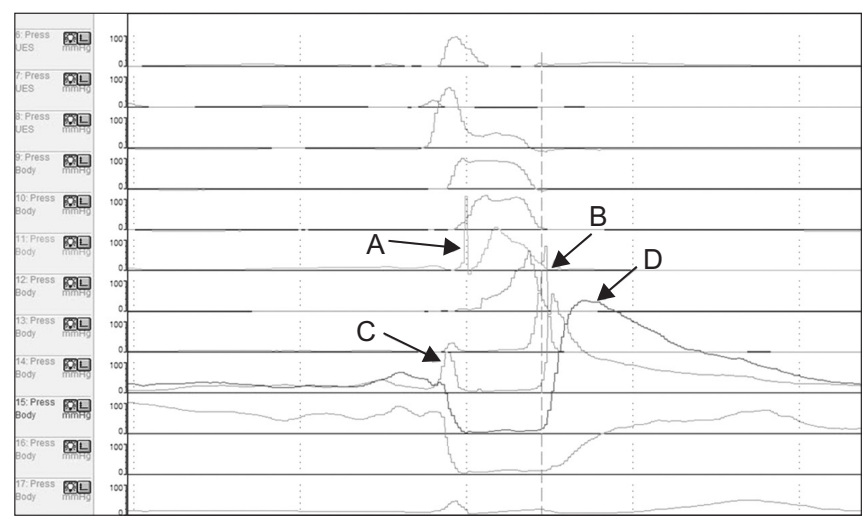

Fig. 1. The epiglottic tilting peak at 1 level higher or lower to epiglottis level as a tongue base pressure (A), low pharyngeal peristaltic shallow and peristaltic peak between TB and UES (B), pre-UES peak (C), and post-UES peak (D). TB, tongue base; UES, upper esophageal sphincter.

Table 1. The visuospatial variables of high-resolution manometry according to rotation maneuver compared to neutral position

\begin{tabular}{|llccc}
\hline Structure & \multicolumn{1}{c}{ Parameter } & Neutral & $\begin{array}{c}\text { Rotate away from } \\
\text { the catheter }\end{array}$ & $\begin{array}{c}\text { Rotate toward } \\
\text { the catheter }\end{array}$ \\
\hline VP & Max pressure $(\mathrm{mmHg})$ & $232.45 \pm 109.74$ & $229.32 \pm 126.39$ & $230.93 \pm 119.60$ \\
& Area $(\mathrm{mmHg} \cdot \mathrm{s})$ & $49.6 \pm 33.44$ & $52.30 \pm 39.83$ & $57.00 \pm 37.88$ \\
& Rise time (s) & $0.16 \pm 0.07$ & $0.14 \pm 0.06$ & $0.17 \pm 0.11$ \\
& Duration (s) & $0.37 \pm 0.15$ & $0.33 \pm 0.19$ & $0.38 \pm 0.19$ \\
\hline TB & Max pressure (mmHg) & $142.14 \pm 29.26$ & $150.35 \pm 34.95$ & $153.96 \pm 27.86$ \\
& Area (mmHg $\cdot \mathrm{s})$ & $53.00 \pm 17.13$ & $52.95 \pm 16.27$ & $55.35 \pm 12.25$ \\
& Rise time (s) & $0.26 \pm 0.08$ & $0.25 \pm 0.01$ & $0.26 \pm 0.04$ \\
\hline LP & Duration (s) & $0.57 \pm 0.14$ & $0.58 \pm 0.08$ & $0.62 \pm 0.08$ \\
\hline UES & Max pressure (mmHg) & $486.58 \pm 152.63$ & $423.38 \pm 139.93^{*}$ & $443.79 \pm 158.46$ \\
& Pre-UES max pressure (mmHg) & $240.58 \pm 120.38$ & $156.45 \pm 99.28^{*}$ & $210.46 \pm 145.71$ \\
& Post-UES max pressure (mmHg) & $452.13 \pm 124.03$ & $388.71 \pm 93.02$ & $407.29 \pm 111.52$ \\
& Min pressure (mmHg) & $-6.21 \pm 5.31$ & $-3.46 \pm 9.40^{*}$ & $-7.26 \pm 6.88$ \\
& Activity time (s) & $0.69 \pm 0.13$ & $0.72 \pm 0.16$ & $0.74 \pm 0.14$ \\
\hline
\end{tabular}

Values are presented as mean \pm standard deviation.

VP, velopharynx; TB, tongue base; LP, lower pharynx; UES, upper esophageal sphincter; max, maximal; min, minimal.

*Significant differences in maneuvers compared to neutral position $(\mathrm{p}<0.05)$. 
lapse between these two points) [13].

\section{Statistical analysis}

SPSS ver. 21.0 software (IBM SPSS, Armonk, NY, USA) was employed for statistical analyses. The results for the variables for different head postures were analyzed using the paired t-test and the neutral posture was compared with head rotation or tilting posture. Then, the data for the head rotation posture were compared with the data for the head tilting posture. Values are presented as mean \pm standard deviation. A significance level was determined with a p-value of 0.05 .

\section{RESULTS}

\section{The VP and TB data on different head posture}

Maximal pressure, area, rise time, and duration of the VP and the TB for head rotation toward and away from the catheter were not significantly different from the neutral posture $(p>0.05)$. No significantly different results were obtained in the head tilting in each direction, as compared to the neutral posture. No significant difference was observed between the head rotation and tilting postures in each direction ( $p>0.05$ ) (Tables 1,2$)$.

\section{The LP and UES data on different head posture}

For head rotation away from the catheter, the maximum pressure in the LP and pre-UES was significantly lower than that at the neutral posture $(\mathrm{p}<0.05)$. For head tilting toward the catheter, the maximal pressure in the LP was significantly higher than that in the case of the head rotation toward the catheter $(\mathrm{p}<0.05)$. The pre-UES maximal pressure in the case of the head tilting toward the catheter position was significantly higher than that in the case of the head rotation toward the catheter $(p<0.05)$. The post-UES maximum pressure in the case of the head tilting away from the catheter was significantly lower than that at the neutral posture $(\mathrm{p}<0.05)$. The UES minimal pressure in the cases of the head rotation and tilting away from the catheter was significantly higher than that at the neutral posture $(\mathrm{p}<0.05)$. Pressure was higher in the LP, although not statistically significant, with head tilting towards the catheter side. Head tilting toward the catheter resulted in UES activity time extension $(\mathrm{p}<0.05)$. The other indices did not show statistically significant difference (Tables 1, 2).

Table 2. The visuospatial variables of high-resolution manometry according to tilting maneuver compared to neutral position

\begin{tabular}{|clccc|}
\hline Structure & \multicolumn{1}{c}{ Parameter } & Neutral & $\begin{array}{c}\text { Tilt away from } \\
\text { the catheter }\end{array}$ & $\begin{array}{c}\text { Tilt toward } \\
\text { the catheter }\end{array}$ \\
\hline VP & Max pressure (mmHg) & $232.45 \pm 109.74$ & $236.00 \pm 119.60$ & $247.11 \pm 107.69$ \\
& Area (mmHg $\cdot \mathrm{s})$ & $49.6 \pm 33.44$ & $56.45 \pm 37.88$ & $58.30 \pm 38.27$ \\
& Rise time (s) & $0.16 \pm 0.07$ & $0.17 \pm 0.10$ & $0.16 \pm 0.08$ \\
\hline TB & Duration (s) & $0.37 \pm 0.15$ & $0.39 \pm 0.19$ & $0.37 \pm 0.19$ \\
& Max pressure (mmHg) & $142.14 \pm 29.26$ & $144.43 \pm 27.86$ & $150.87 \pm 31.20$ \\
& Area (mmHg $\cdot \mathrm{s})$ & $53.00 \pm 17.13$ & $53.85 \pm 12.25$ & $56.65 \pm 17.87$ \\
\hline LP & Rise time (s) & $0.26 \pm 0.08$ & $0.31 \pm 0.08$ & $0.28 \pm 0.03$ \\
\hline UES & Duration (s) & $0.57 \pm 0.14$ & $0.63 \pm 0.08$ & $0.64 \pm 0.12$ \\
\hline & Pax pressure (mmHg) & $486.58 \pm 152.63$ & $425.58 \pm 89.54$ & $519.18 \pm 150.29$ \\
& Post-UES max pressure (mmHg) & $452.13 \pm 124.03$ & $323.93 \pm 112.62^{*}$ & $402.35 \pm 109.47$ \\
\hline & Min pressure (mmHg) & $-6.21 \pm 5.31$ & $-2.99 \pm 5.89^{*}$ & $-8.69 \pm 7.72^{*}$ \\
\hline
\end{tabular}

Values are presented as mean \pm standard deviation.

VP, velopharynx; TB, tongue base; LP, lower pharynx; UES, upper esophageal sphincter; max, maximal; min, minimal.

*Significant differences in maneuvers compared to neutral position $(\mathrm{p}<0.05)$. 
Table 3. The time variables of high-resolution manometry according to rotation maneuver compared to neutral position

\begin{tabular}{llccc}
\hline \multicolumn{1}{c}{ Structure } & \multicolumn{1}{c}{ Parameter } & Neutral & $\begin{array}{c}\text { Rotate away from } \\
\text { the catheter }\end{array}$ & $\begin{array}{c}\text { Rotate toward } \\
\text { the catheter }\end{array}$ \\
\hline Time intervals & VP onset - epiglottis (s) & $0.36 \pm 0.18$ & $0.42 \pm 0.23$ & $0.35 \pm 0.17$ \\
& VP onset - TB onset (s) & $0.14 \pm 0.05$ & $0.21 \pm 0.14$ & $0.14 \pm 0.05$ \\
& VP peak - epiglottis (s) & $0.23 \pm 0.13$ & $0.26 \pm 0.17$ & $0.21 \pm 0.15$ \\
& VP peak - TB peak (s) & $0.31 \pm 0.09$ & $0.32 \pm 0.09$ & $0.26 \pm 0.07$ \\
& VP onset - pre-UES (s) & $0.17 \pm 0.08$ & $0.19 \pm 0.14$ & $0.14 \pm 0.06$ \\
\hline & VP onset - post-UES (s) & $0.92 \pm 0.10$ & $0.98 \pm 0.12$ & $0.91 \pm 0.13$ \\
ROP & VP (cm/s) & $1,810.90 \pm 1,179.98$ & $1,754.28 \pm 1,115.11$ & $1,924.53 \pm 1,234.02$ \\
& TB (cm/s) & $656.43 \pm 292.66$ & $659.62 \pm 236.56$ & $640.31 \pm 169.65$ \\
\hline Velocity of pressure wave & VP onset - post-UES (cm/s) & $7.67 \pm 1.36$ & $7.30 \pm 1.56$ & $7.89 \pm 1.73$ \\
\hline
\end{tabular}

Values are presented as mean \pm standard deviation.

VP, velopharynx; TB, tongue base; UES, upper esophageal sphincter; ROP, rate of pressure generation.

*Significant differences in maneuvers compared to neutral position $(\mathrm{p}<0.05)$.

Table 4. The time variables of high-resolution manometry according to tilting maneuver compared to neutral position

\begin{tabular}{|c|c|c|c|c|}
\hline Structure & Parameter & Neutral & $\begin{array}{l}\text { Tilt away from the } \\
\text { catheter }\end{array}$ & $\begin{array}{l}\text { Tilt toward the } \\
\text { catheter }\end{array}$ \\
\hline \multirow[t]{6}{*}{ Time intervals } & VP onset - epiglottis (s) & $0.36 \pm 0.18$ & $0.38 \pm 0.24$ & $0.39 \pm 0.20$ \\
\hline & VP onset - TB onset (s) & $0.14 \pm 0.05$ & $0.22 \pm 0.12$ & $0.19 \pm 0.11$ \\
\hline & VP peak - epiglottis (s) & $0.23 \pm 0.13$ & $0.26 \pm 0.11$ & $0.25 \pm 0.15$ \\
\hline & VP peak - TB peak (s) & $0.31 \pm 0.09$ & $0.31 \pm 0.07$ & $0.30 \pm 0.08$ \\
\hline & VP onset - pre-UES (s) & $0.17 \pm 0.08$ & $0.22 \pm 0.16$ & $0.20 \pm 0.13$ \\
\hline & VP onset - post-UES (s) & $0.92 \pm 0.10$ & $1.01 \pm 0.16$ & $1.02 \pm 0.16^{*}$ \\
\hline \multirow[t]{2}{*}{ ROP } & $\mathrm{VP}(\mathrm{cm} / \mathrm{s})$ & $1,810.90 \pm 1,179.98$ & 1,977.86 $\pm 1,309.89$ & $1,991.86 \pm 1,237.07$ \\
\hline & $\mathrm{TB}(\mathrm{cm} / \mathrm{s})$ & $656.43 \pm 292.66$ & $509.96 \pm 167.15$ & $551.90 \pm 124.97$ \\
\hline Velocity of pressure wave & VP onset - post-UES (cm/s) & $7.67 \pm 1.36$ & $7.23 \pm 1.78$ & $7.03 \pm 1.42^{*}$ \\
\hline
\end{tabular}

Values are presented as mean \pm standard deviation.

VP, velopharynx; TB, tongue base; UES, upper esophageal sphincter; ROP, rate of pressure generation.

*Significant differences in maneuvers compared to neutral position $(\mathrm{p}<0.05)$.

The time interval data on different head posture

The time intervals in the VP peak and epiglottis, in the VP and TB peaks, and in the VP onset and post-UES; the rate of pressure generation; and the pressure wave velocity in the case of the head tilting toward the catheter were significantly different from those in the case of the head rotation toward the catheter $(\mathrm{p}<0.05)$. The VP onset and the velocity of the post-UES and pressure wave in the case of the head tilting toward the catheter showed statistically significant differences from those at the neutral posture $(\mathrm{p}<0.05)($ Tables 3,4$)$.

\section{DISCUSSION}

Pharyngeal pressure changes according to the head rotation and head tilting postures were measured to analyze the application of compensation techniques to dysphagia treatments. The VP and TB pressures were not affected by the head postures but by the LP and UES pressures.

Conventional esophageal manometry was used for measuring the pressures and time intervals of the two postures on the VFSS and deglutition movements. However, the patients experienced discomfort, and it was difficult to continuously record the pressure changes 
due to the long measurement distance [12]. The HRM system that was used in this study was different from the conventional esophageal manometry in some aspects. First, high-resolution esophageal manometry of the pressure changes during the deglutition process in normal persons indicated that the maximal pharyngeal pressure (TB pressure) was higher than that in the conventional esophageal manometry [12]. This may have been due to the accurate measurements in various areas with the use of more sensors than in the conventional type. The pressure changes in the UES area that plays an important role in the deglutition process could be precisely measured.

In dysphagia patients, the method of head rotation toward the weak side is frequently used for preventing tracheal aspiration and for safe swallowing $[14,15]$. Head rotation toward the weak side can send the bolus to the opposite direction. Consequently, the opposite-side UES opening is prolonged to facilitate swallowing, and the opposite-side UES pressure is lowered to facilitate passing through the UES [14]. Even in normal persons, head rotation not only modifies the direction of food progress but also affects the pharyngeal clearance and the dynamics of the UES [15]. In this study, the UES maximal pressure was significantly higher when the sensors were positioned in the direction towards which the head was turned than at the neutral posture; however, when the sensors were positioned in the opposite direction, the UES maximal pressure was significantly lower than that at the neutral posture. Our study showed similar outcomes to previous studies and confirmed the rationale of head rotation for easy swallowing $[12,15]$.

Tilting the head towards the healthy side is widely used for patients with dysphagia whose foods remain in the paralyzed side due to unilateral oral or pharyngeal weakness [16-18]. When the head is tilted, food flows toward the direction of head tilt. Contrary to expectations, in this study, after the head was tilted toward the catheter, the LP pressure was significantly higher than when the head was tilted away from the catheter. The head-tilting method smoothes the progress of the food by increasing the pressure in the pharynx.

The previous studies on the pressure changes according to various postures using high-resolution esophageal manometry focused on the head rotation and chin tuck postures $[6,12]$. The confirmed increase in pressure in the patients' tilted area with the symptoms of weakness in the unilateral pharynx or tongue, including Wallenberg syndrome, require VFSS test or endoscopy for measuring therapeutic effects according to head tilting.

Our present study had some limitations. First, we evaluated only 10 healthy subjects; however we had a statistically significant result. Second, we did not evaluate patients with dysphagia. Further study to evaluate the effect of volume and texture in dysphagic patients is required.

\section{CONFLICT OF INTEREST}

No potential conflict of interest relevant to this article was reported.

\section{ACKNOWLEDGMENTS}

This research was supported by Basic Science Research Program through the National Research Foundation of Korea (NRF) funded by the Ministry of Science, ICT and Future Planning (NRF-2013R1A1A1004622).

\section{REFERENCES}

1. Lan Y, Xu G, Dou Z, Wan G, Yu F, Lin T. Biomechanical changes in the pharynx and upper esophageal sphincter after modified balloon dilatation in brainstem stroke patients with dysphagia. Neurogastroenterol Motil 2013;25:e821-9.

2. Yoon KJ, Park JH, Park JH, Jung IS. Videofluoroscopic and manometric evaluation of pharyngeal and upper esophageal sphincter function during swallowing. J Neurogastroenterol Motil 2014;20:352-61.

3. Savarino E, Zentilin P, Savarino V, Tenca A, Penagini $\mathrm{R}$, Clarke JO, et al. Functional testing: pharyngeal $\mathrm{pH}$ monitoring and high-resolution manometry. Ann N Y Acad Sci 2013;1300:226-35.

4. Clarke JO, Gyawali CP, Tatum RP. High-resolution manometry. Ann N Y Acad Sci 2011;1232:349-57.

5. Hila A, Castell JA, Castell DO. Pharyngeal and upper esophageal sphincter manometry in the evaluation of dysphagia. J Clin Gastroenterol 2001;33(5):355-61.

6. Takasaki K, Umeki H, Kumagami H, Takahashi H. Influence of head rotation on upper esophageal sphincter pressure evaluated by high-resolution manometry system. Otolaryngol Head Neck Surg 2010;142:214-7.

7. Perlman AL, Schultz JG, VanDaele DJ. Effects of age, 
gender, bolus volume, and bolus viscosity on oropharyngeal pressure during swallowing. J Appl Physiol (1985) 1993;75:33-7.

8. Baek SS, Park SB, Lee SG, Lee KM, Kim SH. The effect of neck posture in swallowing of stroke patients. J Korean Acad Rehabil Med 1997;21:8-12.

9. Kahrilas PJ, Logemann JA, Lin S, Ergun GA. Pharyngeal clearance during swallowing: a combined manometric and videofluoroscopic study. Gastroenterology 1992;103:128-36.

10. Fox MR, Bredenoord AJ. Oesophageal high-resolution manometry: moving from research into clinical practice. Gut 2008;57:405-23.

11. Mielens JD, Hoffman MR, Ciucci MR, Jiang JJ, McCulloch TM. Automated analysis of pharyngeal pressure data obtained with high-resolution manometry. Dysphagia 2011;26:3-12.

12. McCulloch TM, Hoffman MR, Ciucci MR. High-resolution manometry of pharyngeal swallow pressure events associated with head turn and chin tuck. Ann Otol Rhinol Laryngol 2010;119:369-76.

13. Mielens JD, Hoffman MR, Ciucci MR, McCulloch TM,
Jiang JJ. Application of classification models to pharyngeal high-resolution manometry. J Speech Lang Hear Res 2012;55:892-902.

14. Logemann JA, Kahrilas PJ, Kobara M, Vakil NB. The benefit of head rotation on pharyngoesophageal dysphagia. Arch Phys Med Rehabil 1989;70:767-71.

15. Ohmae Y, Ogura M, Kitahara S, Karaho T, Inouye T. Effects of head rotation on pharyngeal function during normal swallow. Ann Otol Rhinol Laryngol 1998;107:344-8.

16. Rasley A, Logemann JA, Kahrilas PJ, Rademaker AW, Pauloski BR, Dodds WJ. Prevention of barium aspiration during videofluoroscopic swallowing studies: value of change in posture. AJR Am J Roentgenol 1993;160:1005-9.

17. Logemann JA. Role of the modified barium swallow in management of patients with dysphagia. Otolaryngol Head Neck Surg 1997;116:335-8.

18. Beom J, Han TR. Treatment of dysphagia in patients with brain disorders. J Korean Med Assoc 2013;56:715. 